\title{
Challenges and perspective of cancer patients during the COVID-19 pandemic and the Lebanese financial crisis: a multicentric cross-sectional study
}

\author{
Rashad Nawfal ${ }^{1, a}$ (D), Jad Kassem ${ }^{1}$, Hassan Salame ${ }^{2, b}$ (D), Ali Kassem ${ }^{3}$, Pascale Salameh ${ }^{4,5,6, c}$ (D) and Bassam F Matar \\ ${ }^{1}$ Faculty of Medical Sciences, Lebanese University, 3 Campus Lebanese University - Hadath, Beirut, Lebanon \\ ${ }^{2}$ Department of Internal Medicine, Faculty of Medical Sciences, Lebanese University, 3 Campus Lebanese University - Hadath, Beirut, Lebanon \\ ${ }^{3}$ Department of Surgery, Faculty of Medical Sciences, Lebanese University, 3 Campus Lebanese University - Hadath, Beirut, Lebanon \\ ${ }^{4}$ INSPECT-LB: Institut National de Santé Publique, Épidémiologie Clinique et Toxicologie-Liban, Beirut 00000, Lebanon \\ ${ }^{5}$ Department of Primary Care and Population Health, University of Nicosia Medical School, Nicosia 2408, Cyprus \\ ${ }^{6}$ Faculty of Pharmacy, Lebanese University, 3 Campus Lebanese University - Hadath, Beirut, Lebanon \\ ${ }^{7}$ Department of Internal Medicine, Faculty of Medical Sciences, Division of Haematology and Oncology, Lebanese University, 3 Campus Lebanese University \\ - Hadath, Beirut, Lebanon \\ ahttps://orcid.org/0000-0001-5428-5660 \\ bhttps://orcid.org/0000-0002-3804-6173 \\ chttps://orcid.org/0000-0002-4780-0772
}

\begin{abstract}
Lebanese cancer patients are facing a war on two fronts, between the COVID-19 pandemic and one of the most severe financial crises globally in recent times. This multicentric cross-sectional study was conducted, aiming to analyse challenges and perspective of this particularly vulnerable population. A questionnaire was prepared to assess socio-demographic data, challenges faced during the pandemic, perspectives concerning cancer and COVID-19, a scale was also validated to assess knowledge level regarding COVID-19 in this population. Patients were interviewed in chemotherapy units from four different private and public hospitals in Lebanon during December 2020 and March-June 2021. In total, 272 patients were interviewed (median age, 57 years, range, 22-90 years). Concerning salary during the pandemic, it changed negatively (45.6\%), or did not change $(7.7 \%)$, while $46.7 \%$ of participants did not work. Some challenges such as transportation problems (39\%), inability to reach their physician by phone $(16.9 \%)$, deferral of chemotherapy dates (31.6\%), difficulty finding chemotherapy medications (49.6\%) were more likely to be reported by patients receiving chemotherapy in public compared to private hospitals ( $p<0.01$ for each). Other challenges include not being able to find non-cancer-related medications (71.3\%), this challenge being increased when comparing December 2020 with March-June $2021(p<0.02)$. Using a multivariate analysis, the best predictor for increased knowledge about COVID-19 was higher levels of education $(p<0.001)$. In conclusion, this study shows that cancer patients in Lebanon are facing many challenges that complicate different aspects of health. Perspective and challenges of these patients must be taken into consideration in order to deliver better care to our patients in these unprecedented times.
\end{abstract}

Keywords: COVID-19, cancer, knowledge, challenges, delivery of health care, Lebanon
Correspondence to: Rashad Nawfal Email: rachad.nawfal@gmail.com

ecancer 2022, 16:1359

https://doi.org/10.3332/ecancer.2022.1359

Published: $24 / 02 / 2022$

Received: 07/10/2021

Publication costs for this article were supported by ecancer (UK Charity number 1176307).

Copyright: $($ c the authors; licensee ecancermedicalscience. This is an Open Access article distributed under the terms of the Creative Commons Attribution License (http:// creativecommons.org/licenses/by/4.0), which permits unrestricted use, distribution, and reproduction in any medium, provided the original work is properly cited. 


\section{Background}

The severe acute respiratory syndrome coronavirus 2 (SARS-CoV-2) virus has resulted in an ongoing pandemic. At the time of writing (August 2021), and according to the World Health Organization, over 215 million people have developed the resulting illness, COVID-19, causing more than 4.48 million deaths worldwide. Most people have been either directly or indirectly affected by this pandemic in many ways from healthcare to the economy. However, there are certain subgroups such as cancer patients that have been disproportionately affected, as according to multiple studies [1, 2], cancer patients tend to have worse outcomes when infected with SARS-CoV-2.

Moreover, cancer patients are at a high risk of immunosuppression that can be caused by the malignancy itself or the treatment. Lack of immunity makes these patients prone to serious infections, especially COVID-19, that can aggravate their condition and increase the rate of unnecessary hospitalisation that can delay the treatment of cancer, hence affecting the prognosis negatively [3]. Patients that suffer from haematologic cancer and those who are receiving chemotherapy are at a higher risk of immune deficiency [4]. In comparison to the general population, the rate of contracting SARS-CoV-2 in cancer patients is higher according to some reports, especially in male gender and haematological malignancies [5, 6], and frequently leads to a worsened condition and a very poor prognosis [7]. A study analysed health records of the US Veterans Affairs Healthcare System for the prevalence of COVID-19 infection in cancer patients. Of 22,914 cancer patients, a higher prevalence of COVID-19 infection was found in people with haematologic malignancies compared to solid tumours (10.9\% versus $7.8 \%, p$ $<0.001)[5]$.

Cancer by itself is one of the main causes of death globally, and its burden is considerable in countries of all income levels. However, this burden can be decreased through proper treatment and comfort care provided by the country and internationally [8]. Healthcare related to cancer may however be reduced due to the COVID-19 situation, since hospitals are getting more and more overwhelmed and saturated from the current situation. The COVID-19 pandemic is not only delaying the treatment of malignancies, but also new diagnosis. Some haematologic malignancies and solid tumours need rapid intervention for treatment or diagnosis, other malignancies do not [9].

In Lebanon, there has been a total of 8,031 deaths thus far (26th of August 2021, Ministry of Public Health), with a reported death rate of 1,172 /million person, which has led to a shortage in hospital beds and medical resources [10]. In addition, Lebanon is currently experiencing the third most severe financial crisis worldwide since the mid-19th century according to the World Bank [11], with a money depreciation of more than $90 \%$. There is a massive shortage of medications which led to many cancer patients having a hard time accessing chemotherapy as well as other drugs, the wealthiest of patients are buying their medications from abroad [12]. Cancer patients in Lebanon are facing a 'war on two fronts'. The first front is facing one of the most severe financial crises and medication shortages in recent times, and the second is facing the COVID-19 pandemic and the potential implications of this pandemic on the evolution of their cancer.

The aim of this study was to uncover the challenges faced by cancer patients in Lebanon during this critical period, assess level of knowledge regarding COVID-19 and find predictors of increased knowledge, as well as to assess different perspectives concerning the novel coronavirus and their malignancy.

\section{Methods}

\section{Study design}

This is a cross-sectional, multicentric study, conducted in multiple private and public chemotherapy units, from rural and urban areas in Lebanon. Namely, Rafik Hariri University Hospital, Al Zahraa Hospital University Medical Center, Dar al Amal University Hospital and Saint Charles Hospital.

In total, 272 cancer patients aged between 22 and 90 consented to participate in this study. Thirty patients were interviewed at Dar al Amal University Hospital during December 2020. The rest were interviewed between March 2021 and June 2021 in all four chemotherapy units included in this study. Patients were interviewed by the investigator who was recording all responses on the questionnaire form. The 
interview was performed in Arabic, and then the questionnaire was translated by two professional translators. After making sure that both versions matched perfectly, answers were filled on the translated English version for all participants.

The questionnaire consisted of four parts: the first part asks about socio-demographic data. The second part asks about challenges faced by cancer patients. The third part is a knowledge scale we validated to use on this specific population. Finally, the fourth part asks about perspectives regarding COVID-19 and their malignancy.

\section{Validation and reliability of the scale}

The part aiming to assess knowledge level regarding COVID-19 is a 3-point Likert scale ranging from $0=$ disagree, $1=$ don't know, $2=$ agree. 'Don't know' was added as an answer in order to offer a middle response alternative to people who do not possess a clear-cut opinion on the statement provided [13]. Statements $(2,4,5,6,7$ and 8$)$ were scored in reverse order of the above-mentioned scoring as the correct answer for these statements was 'disagree'.

Initially, the literature review was conducted on the Centers for Disease Control and Prevention and the World Health Organization's websites to develop a data pool of some common statements and misconceptions regarding COVID-19, which was then reviewed and approved by two oncologists and an expert in questionnaire formulation. After reviewing and corrections, we narrowed down the questionnaire to eight final statements aiming to assess knowledge level regarding COVID-19 (See Supplementary File).

Validation of the questionnaire was assessed by ways of discriminant validity, face validity and construct validity. Discriminant validity was assessed using Fornell-Larcker criterion suggested in 1981 for assessing discriminant validity [14]. According to this criterion, if the square root of the Average Variance Extracted of our two components is greater than the correlation coefficient between component 1 and component 2, then the model satisfies the discriminant validity criterion. Pearson's correlation between our two components yielded a value of 0.297 with $p<0.001$. The square root of the Average Variance Extracted of our two components was equal to 0.698. Meaning that our scale presents an adequate discriminant validity.

Face validity was established by the experts as well as the participants who stated they had no difficulty understanding and answering to all eight statements. To assess Construct validity, a Principal Component Analysis was performed, and yielded a Kaiser-Meyer-Olkin value of 0.785 which is satisfactory, and the Bartlett's test for sphericity was significant $(p<0.001)$ indicating that the factor analysis is suitable.

Two components were then extracted for Principal Component Analysis, both above the eigenvalue limit set at 1.0 according to the scree plot for factor identification (see Figure 1). The percentage of total variance explained by these two components was $47.427 \%$, component 1 explains 33.303\% and component 2 explains $14.124 \%$ of the total variance. Factor 1 represents erroneous statements, and factor 2 represents true statements. Rotation was done using Varimax with Kaiser normalisation, all items had factor loadings on a single factor greater than 0.3 and ranging from 0.403 to 0.823 (see Table 1) which is acceptable.

As to sample size, the acceptable ratio of the number of people to the number of measured variables should exceed 10 to perform exploratory factor analysis. Our questionnaire was completed by 272 cancer patients in total, providing a ratio of 34 in total to our scale containing 8 items, meaning that our sample size is adequate.

Reliability was established using Cronbach's alpha on the final scale answers, a score of 0.7 and higher can be considered as acceptable [15]. Cronbach's alpha for this scale was equal to 0.711.

\section{Inclusion and exclusion criteria}

Inclusion criteria included cancer patients from multiple oncology clinics receiving chemotherapy treatment in any of the four chemotherapy units and during the timeframe this study was conducted in. All included participants completed the consent form after having it thoroughly explained by an investigator.

The exclusion criteria included non-cooperative patients, patients who do not reside in Lebanon, and minors under 18 years of age. 


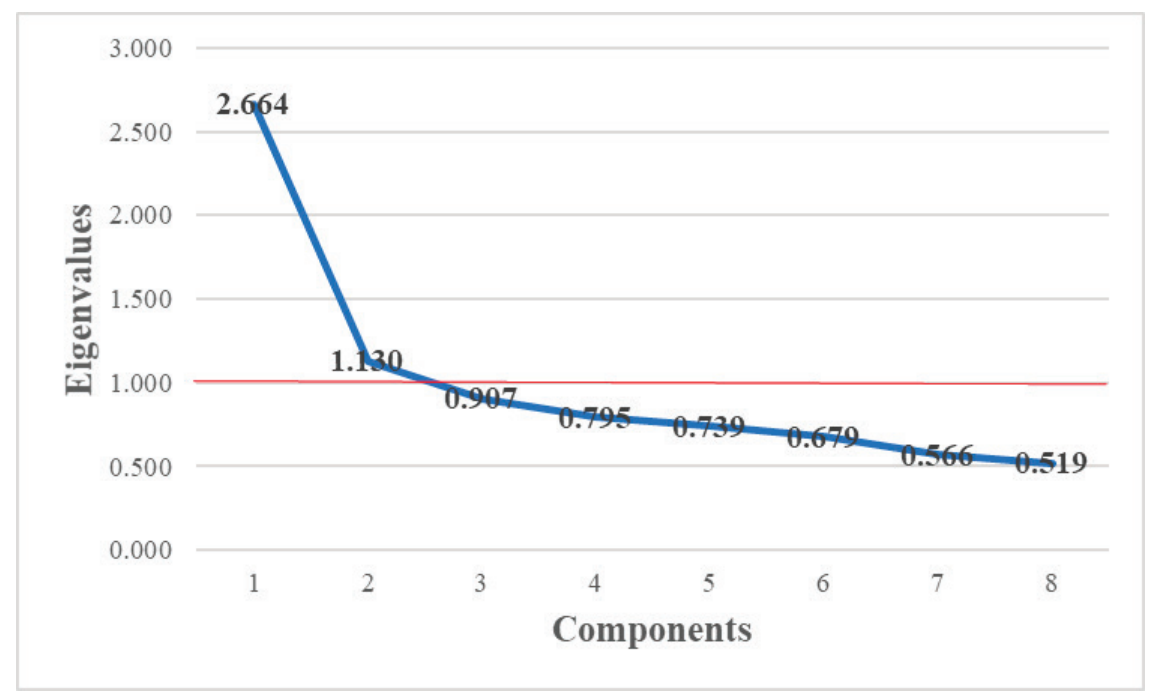

Figure 1. Scree plot for factor identification.

Table 1. Rotated component matrix for Principal Component Analysis.

\begin{tabular}{|l|c|c|}
\hline \multirow{2}{*}{} & \multicolumn{2}{|c|}{ Component } \\
\cline { 2 - 3 } & 1 & 2 \\
\hline 4- COVID-19 can spread through food, through the digestive system (Disagree) & 0.687 & \\
\hline 7- COVID-19 can spread through the water of swimming pools (Disagree) & 0.679 & \\
\hline 5- Hot beverages protect from contracting COVID-19 (Disagree) & 0.677 & \\
\hline $\begin{array}{l}\text { 2- COVID-19 is always accompanied by a loss of taste and smell, in 100\% of people who contract the } \\
\text { virus (Disagree) }\end{array}$ & 0.675 \\
\hline 6- Eating garlic protects from contracting COVID-19 (Disagree) & 0.603 \\
\hline 8- Wearing a face shield without a mask protects from contracting COVID-19 (Disagree) & 0.403 \\
\hline 3- COVID-19 can spread through cough (Agree) & & 0.823 \\
\hline 1- Infected children showing no symptoms can spread the virus to others (Agree) & & 0.713 \\
\hline
\end{tabular}

Extraction Method: Principal Component Analysis

Rotation method: Varimax with Kaiser normalisation

Two components extracted: Factor 1: Erroneous statements; Factor 2: True statements

Agree /Disagree in the parentheses denotes the intended correct answer

\section{Statistical analysis}

Statistical analyses were carried out on R software version 4.0.5 (R Foundation for Statistical computing). Descriptive statistics were reported as median, interquartile range and range for age; median, interquartile range, range and Standard Deviation for knowledge score, and frequency with percentages for categorical variables. Categorical variables were described using counts and percentages. Age and total score of knowledge towards COVID-19 were categorised, each, into two groups with their medians ( 57 and 9, respectively) serving as the cut-off values. Univariate logistic regression was used to assess the association between the presence of challenges (dependent variable) and the funding type of the hospital where patients have received chemotherapy (public versus private as independent variable). Multivariate logistic 
regression analysis was conducted to assess the factors that are associated with the knowledge score being above or below average. Only factors with a $p$-value below 0.2 on Chi-squared test were included in multivariate logistic regression. The model was not found to be badly fitted on Hosmer-Lemeshow goodness of fit test for multivariate logistic regression ( $p$-value $=0.132$ ). For logistic regression analyses, oddsratios, 95\% confidence interval for odds-ratios and $p$-values were reported. Statistical significance level was set at $p$-value $<0.05$.

\section{Ethical considerations}

The research proposal was first approved by the ethics committees of all medical centres involved in this study. Institutional Review Board (IRB) approval was granted from Rafik Hariri University Hospital on the 1st of March 2021 as well as from Al Zahraa Hospital University Medical Center with reference number 4/2021. A written informed consent form was also completed by all the participants. An Investigator was present at all times, and explained the anonymity and confidentiality of the data as well as patients having the right to drop out of the study at any time without any retributions or repercussions.

\section{Results}

\section{Socio-demographic data}

Of the 272 patients who participated in this study, $37.1 \%$ were males and $62.9 \%$ were females, median age was 57 years, interquartile range was 46-67 and range was 22-90. The percentage of patients who were infected and recovered from COVID-19 before participating in this study was $25 \%$. Concerning the funding type of the hospital where patients received chemotherapy, $19.9 \%$ of patients received their treatment in a public hospital (Rafik Hariri University Hospital), the remaining $80.1 \%$ of patients at Private hospitals. $42.6 \%$ of participants received their treatment outside the Greater Beirut area in Baalbek (Dar Al Amal University Hospital) and the remaining $57.4 \%$ inside the Greater Beirut area. Regarding the intent of treatment, it was curative in $94.8 \%$ and palliative in $5.2 \%$. The summary of socio-demographic data is shown in Table 2.

\section{Challenges faced during the pandemic}

The most commonly faced challenge by participants in this study was not being able to find non-chemotherapy drugs such as Hypertension and Diabetes medications, Antibiotics or Non-steroidal anti-inflammatory drugs (71.3\%). Prevalence of various challenges assessed in this study can be found in Table 3.

After comparing the prevalence of all challenges based on the funding source of the hospital, it can be noted that 'transportation problems from residence to the hospital' (39\% of all participants), 'not always being able to reach their physician online by phone calls or WhatsApp' (15.8\% of all participants), 'deferral of radiotherapy/chemotherapy dates' (31.6\% of all participants) and 'not always being able to find chemotherapy medications' (49.6\% of all participants) were all challenges more likely to be observed in Public compared to Private hospitals ( $p$ $<0.001, p<0.001, p<0.01$ and $p<0.001$, respectively). The full comparison between the prevalence of challenges in Private and Public hospitals can be found in Table 4.

\section{Knowledge of cancer patients regarding COVID-19}

In regard to responses to the scale to assess knowledge level towards COVID-19, median score was 9, standard deviation was 3.68, interquartile range was 6-12 and range was 1-16. The most common misconception in this population was that garlic could protect from contracting COVID-19 (48.5\% answered Wrong), other common misconceptions include that 'hot beverages could protect from contracting COVID-19' (44.5\% answered Wrong), and that 'COVID-19 can be transmitted through the water of swimming pools' (40.8\% answered Wrong). A description of the items and answers to this scale can be found in Table 5. 
Table 2. Socio-demographic data.

\begin{tabular}{|c|c|}
\hline & $n(\%)$ \\
\hline \multicolumn{2}{|l|}{ Location of hospitalisation } \\
\hline Zahraa Hospital University Medical Center & $86(31.6 \%)$ \\
\hline Rafic Hariri University Hospital & $54(19.9 \%)$ \\
\hline Dar al Amal University Hospital & $116(42.6 \%)$ \\
\hline Saint Charles Hospital & $16(5.9 \%)$ \\
\hline \multicolumn{2}{|l|}{ Gender } \\
\hline Male & 101 (37.1\%) \\
\hline Female & $171(62.9 \%)$ \\
\hline \multicolumn{2}{|l|}{ Intent of treatment } \\
\hline Curative & $258(94.8 \%)$ \\
\hline Palliative & $14(5.2 \%)$ \\
\hline \multicolumn{2}{|l|}{ Time of diagnosis } \\
\hline Before the pandemic & 132 (48.5\%) \\
\hline During the pandemic & $140(51.5 \%)$ \\
\hline \multicolumn{2}{|l|}{ Were you diagnosed with COVID-19? } \\
\hline Yes & $68(25 \%)$ \\
\hline No & $204(75 \%)$ \\
\hline \multicolumn{2}{|l|}{ Education status } \\
\hline Illiterate & $36(13.2 \%)$ \\
\hline Elementary school & 132 (48.6\%) \\
\hline High school graduate & $68(25 \%)$ \\
\hline College graduate & $36(13.2 \%)$ \\
\hline \multicolumn{2}{|c|}{ Did your monthly income change during the pandemic } \\
\hline Yes, negatively & $124(45.6 \%)$ \\
\hline Yes, positively & 0 \\
\hline No & $21(7.7 \%)$ \\
\hline I don't work & $127(46.7 \%)$ \\
\hline \multicolumn{2}{|l|}{ Site of malignancy } \\
\hline Solid tumours & $223(81.99 \%)$ \\
\hline Breast & 103 (37.9\%) \\
\hline Lung & $34(12.5 \%)$ \\
\hline Colon & $24(8.8 \%)$ \\
\hline Ovary & $12(4.4 \%)$ \\
\hline Stomach & $8(2.9 \%)$ \\
\hline Bladder & $7(2.6 \%)$ \\
\hline
\end{tabular}


Table 2. Socio-demographic data. (Continued)

\begin{tabular}{|l|c|}
\hline Prostate & $6(2.2 \%)$ \\
\hline Kidney & $4(1.5 \%)$ \\
\hline Larynx & $4(1.5 \%)$ \\
\hline Liver & $4(1.5 \%)$ \\
\hline Cervix & $3(1.1 \%)$ \\
\hline Cholangiocarcinoma & $2(<1 \%)$ \\
\hline Melanoma & $2(<1 \%)$ \\
\hline Adrenal glands & $1(<1 \%)$ \\
\hline Endometrium & $1(<1 \%)$ \\
\hline Ewing sarcoma & $1(<1 \%)$ \\
\hline Medulloblastoma & $1(<1 \%)$ \\
\hline Nasopharynx & $1(<1 \%)$ \\
\hline Oropharynx & $1(<1 \%)$ \\
\hline Pancreas & $1(<1 \%)$ \\
\hline Parotid & $1(<1 \%)$ \\
\hline Testicles & $1(<1 \%)$ \\
\hline Thymus & $1(<1 \%)$ \\
\hline Haematologic malignancies & $47(17.28 \%)$ \\
\hline Hodgkin lymphoma & $22(8.1 \%)$ \\
\hline Non-Hodgkin lymphoma & $10(3.7 \%)$ \\
\hline Multiple myeloma & $6(2.2 \%)$ \\
\hline Acute myeloid leukaemia & $3(1.1 \%)$ \\
\hline Myelodysplastic syndrome & $3(1.1 \%)$ \\
\hline Chronic myeloid leukaemia & $2(<1 \%)$ \\
\hline Hairy cell leukaemia & $1(<1 \%)$ \\
\hline Unknown primary & $2(<1 \%)$ \\
\hline
\end{tabular}

$n$, frequency; \%, percentage

Concerning the multivariate analysis to find predictors of increased knowledge level regarding COVID-19, all variables included in the analysis had a $p$-value $<0.2$ in bivariate analysis. Variables included were age, intent of treatment, prior diagnosis of COVID-19 infection, education status, funding source of the hospital offering treatment, level of worry towards contracting COVID-19, fear of cancer compared to COVID-19 and awareness that chemotherapy could decrease immunity and increase health-related risks due to COVID-19. The best predictors were higher levels of education, such as being a High School Graduate $(p<0.001)$ and a College Graduate $(p<0.001)$. Results of the multivariate analysis can be found in Table 6.

\section{Perspective regarding COVID-19 and cancer}

Concerning the reported level of worry regarding COVID-19, 30.9\% reported a minimal level of worry, 31.6\% reported an average level of worry and $37.5 \%$ reported a maximal level of worry. As to fear from cancer and COVID-19, $24.3 \%$ reported that they feared COVID-19 more 
than cancer, $61.8 \%$ reported that they feared cancer more than COVID-19, $11.4 \%$ feared both equally and $2.6 \%$ stated that they feared none. As to the knowledge that chemotherapy could lower the immunity and thus increase the chance of health-related risks due to COVID-19, $75.7 \%$ reported that it could, $22.1 \%$ reported that it could not, and $2.1 \%$ did not know. Finally, in regard to preventive measures at home against COVID-19, 13.2\% used face masks and social distancing only, $23.9 \%$ did self-quarantine at home only, $28 \%$ did both of the above, and $34.9 \%$ did none of the above. The full results of perspectives regarding COVID-19 and cancer can be found in Table 7.

Table 3. Challenges faced by cancer patients.

\begin{tabular}{|c|c|c|}
\hline & $\begin{array}{l}\text { Faced the } \\
\text { challenge } \\
n(\%)\end{array}$ & $\begin{array}{l}\text { Did not face the } \\
\text { challenge } \\
n(\%)\end{array}$ \\
\hline $\begin{array}{l}\text { Availability of non-chemotherapy medications (i.e., Aspirin, Paracetamol, Hypertension and Diabetes } \\
\text { medications...) }\end{array}$ & $194(71.3 \%)$ & $78(28.7 \%)$ \\
\hline Availability of chemotherapy medications & $135(49.6 \%)$ & $137(50.4 \%)$ \\
\hline Increase of the consultation fees with your Doctor & $117(43 \%)$ & $155(57 \%)$ \\
\hline Transportation problems from residence to hospital & $106(39 \%)$ & $166(61 \%)$ \\
\hline Deferral of radiotherapy/chemotherapy dates & $86(31.6 \%)$ & $186(68.4 \%)$ \\
\hline Difficulty in maintaining precautionary measures (social distancing, wearing facemask etc...) & $69(25.4 \%)$ & $203(74.6 \%)$ \\
\hline Are you able to reach your doctor online (i.e., WhatsApp, Phone calls etc...) & $46(15.8 \%)$ & $226(83.2 \%)$ \\
\hline Long waiting hours beyond appointment time & $35(12.9 \%)$ & $237(87.1 \%)$ \\
\hline Availability of hospital beds & 34 (12.5\%) & 238 (87.5\%) \\
\hline
\end{tabular}

$n$, frequency; \%, percentage

Table 4. Challenges in private compared to public hospitals. Statistically significant values with $p<0.05$ are highlighted in bold.

\begin{tabular}{|c|c|c|c|}
\hline & \multicolumn{2}{|c|}{ Location of hospitalisation } & \multirow[b]{2}{*}{$p$-value } \\
\hline & $\begin{array}{c}\text { Private hospitals } \\
n(\%)\end{array}$ & $\begin{array}{c}\text { Public hospital } \\
n(\%)\end{array}$ & \\
\hline Transportation problems from residence to hospital & $73(33.5 \%)$ & $33(61.1 \%)$ & $<0.001$ \\
\hline Are you able to reach your doctor online (i.e. WhatsApp, Phone calls etc...) & $30(13.8 \%)$ & $16(29.6 \%)$ & $<0.001$ \\
\hline $\begin{array}{l}\text { Difficulty in maintaining precautionary measures (social distancing, wearing } \\
\text { facemask etc...) }\end{array}$ & $54(24.8 \%)$ & $15(27.8 \%)$ & 0.650 \\
\hline Deferral of radiotherapy/chemotherapy dates & $60(27.5 \%)$ & $26(48.2 \%)$ & 0.004 \\
\hline Availability of chemotherapy medications & $96(44.0 \%)$ & 39 (72.2\%) & $<0.001$ \\
\hline $\begin{array}{l}\text { Availability of non-chemotherapy medications (i.e. Aspirin, Paracetamol, } \\
\text { Hypertension and Diabetes medications...) }\end{array}$ & $156(71.6 \%)$ & $38(70.4 \%)$ & 0.863 \\
\hline Long waiting hours beyond appointment time & $29(13.3 \%)$ & $6(11.1 \%)$ & 0.667 \\
\hline Availability of hospital beds. & $27(12.4 \%)$ & $7(13.0 \%)$ & 0.909 \\
\hline Increase of the consultation fees with your Doctor. & $92(33.8 \%)$ & $25(9.2 \%)$ & 0.587 \\
\hline
\end{tabular}

$n$, frequency; \%, percentage of challenge when present 
Table 5. Patients' responses to Knowledge Scale.

\begin{tabular}{|c|c|c|c|}
\hline Knowledge items & Correct & Wrong & Don't know \\
\hline 1- Infected children showing no symptoms can spread the virus to others (Agree) & $161(59.2)$ & $41(15.1)$ & $70(25.7)$ \\
\hline $\begin{array}{l}2-\text { COVID-19 is always accompanied by a loss of taste and smell, in } 100 \% \text { of people who contract } \\
\text { the virus (Disagree) }\end{array}$ & $111(40.8)$ & $117(43.0)$ & $44(16.2)$ \\
\hline 3- COVID-19 can spread through cough (Agree) & $236(86.8)$ & $15(5.5)$ & $21(7.7)$ \\
\hline 4- COVID-19 can spread through food, through the digestive system (Disagree) & $101(37.1)$ & $90(33.1)$ & $81(29.8)$ \\
\hline 5- Hot beverages protect from contracting COVID-19 (Disagree) & $90(33.1)$ & $121(44.5)$ & $61(22.4)$ \\
\hline 6- Eating garlic protects from contracting COVID-19 (Disagree) & $73(26.9)$ & $132(48.5)$ & $67(24.6)$ \\
\hline 7- COVID-19 can spread through the water of swimming pools (Disagree) & $67(24.6)$ & $111(40.8)$ & $94(34.6)$ \\
\hline 8- Wearing a face shield without a mask protects from contracting COVID-19 (Disagree) & $169(62.1)$ & $56(20.6)$ & $47(17.3)$ \\
\hline
\end{tabular}

Agree/Disagree in the parentheses denotes the intended correct answer

\section{Discussion}

This study is the first of its kind to assess the challenges, as well as the perspective and knowledge concerning COVID-19 of cancer patients during the Lebanese financial Crisis and concomitant COVID-19 pandemic. In total, $62.9 \%$ of participants in this study were women and median age was 57 . This finding was expected as breast cancer is one of the most common malignancies in Lebanon. This type of cancer also presents at a median age of 50 in Lebanon, compared to a median age of 63 years in western countries [16], which could account for the female predominance as well as the median age in this study. As of the end of June 2021, approximately $7.97 \%$ of the Lebanese population contracted COVID-19 at some point during the pandemic according to the Lebanese Ministry of Public Health [10]. In this study, 25\% of participants had contracted and recovered from COVID-19, which could hint towards an inadequacy in testing for this virus in the general population in Lebanon. Concerning the education status in this population, $13.2 \%$ of participants were illiterate which is in concordance with the United Nations Educational, Scientific and Cultural Organization statistics in Lebanon [17]. Finally, in regard to the reported change in monthly income, $45.6 \%$ reported a decrease, $7.7 \%$ reported no change and $0 \%$ reported an increase in monthly income. $46.7 \%$ reported they did not work. Meaning the majority of cancer patients in Lebanon have experienced a financial setback during this period.

For challenges faced by cancer patients, a somewhat similar study was done on 36 cancer patients in India by Mitra and Basu [18]. Challenges assessed were transportation from residence to the hospital which was faced by $77.8 \%$ compared to $39 \%$ in this study. Another similar challenge was non availability of chemotherapy medications which was faced by $22.2 \%$ compared to $49.6 \%$ in this study. This high prevalence for this challenge was expected as Lebanon is facing a shortage in all kinds of medications, especially chemotherapy drugs [12]. Concerning difficulty finding non-chemotherapy medications such as non-steroidal anti-inflammatory drugs, antibiotics, hypertension and diabetes medications, this challenge was faced by $71.3 \%$ of all participants in this study. This challenge also increased during the timeline of the study, when comparing December 2020 with March until June $2021(p<0.02)$ as shown in Figure 2.

Concerning the knowledge of cancer patients regarding COVID-19, statements that only a minority of participants had a correct answer for were: COVID-19 can spread through the water of swimming pools (24.6\% answered correctly). Eating garlic can protect from contracting COVID-19 (26.9\% answered correctly). Hot beverages can protect from contracting COVID-19 (33.1\% answered correctly). COVID-19 can spread through food, through the digestive system (37.1\%). As well as that COVID-19 is always accompanied by a loss of taste and smell, in $100 \%$ of people who contract the virus (40.8\%). These misconceptions can be caused by lack of access to information, lack of communication with their physician, they can also be caused by different sources of media spreading misinformation [19], or simply due to inability to recall information. 
Table 6. Factors associated with better knowledge towards COVID-19.

\begin{tabular}{|c|c|c|c|c|}
\hline & Knowledge & & & \\
\hline & $\begin{array}{c}\text { Below average } \\
n(\%)\end{array}$ & $\begin{array}{c}\text { Above average } \\
n(\%)\end{array}$ & $p$-value & Adjusted OR (95\%CI) \\
\hline \multicolumn{5}{|l|}{ Age categories } \\
\hline$\leq 57$ years & $65(43.0 \%)$ & $72(59.5 \%)$ & \multirow[t]{2}{*}{0.079} & \multirow[t]{2}{*}{$0.61(0.34-1.06)$} \\
\hline$>57$ years & $86(57.0 \%)$ & $49(40.5 \%)$ & & \\
\hline \multicolumn{5}{|l|}{ Intent of treatment } \\
\hline Curative & 139 (92.1\%) & $119(98.3 \%)$ & \multirow[t]{2}{*}{0.144} & \multirow[t]{2}{*}{$0.31(0.05-1.25)$} \\
\hline Palliative & $12(7.9 \%)$ & $2(1.7 \%)$ & & \\
\hline \multicolumn{5}{|c|}{ Were you diagnosed with COVID-19? } \\
\hline Yes & $30(19.9 \%)$ & $38(31.4 \%)$ & \multirow[t]{2}{*}{0.207} & \multirow[t]{2}{*}{$0.67(0.35-1.25)$} \\
\hline No & $120(79.5 \%)$ & $83(68.6 \%)$ & & \\
\hline \multicolumn{5}{|l|}{ Education status } \\
\hline Illiterate & $30(19.9 \%)$ & $6(5.0 \%)$ & \multicolumn{2}{|c|}{ Reference group } \\
\hline Elementary school & $87(57.6 \%)$ & $45(37.2 \%)$ & 0.079 & $2.45(0.95-7.22)$ \\
\hline High school graduate & $27(17.9 \%)$ & $41(33.9 \%)$ & $<0.001$ & $6.32(2.31-19.67)$ \\
\hline College graduate & $7(4.6 \%)$ & $29(24.0 \%)$ & $<0.001$ & $19.27(5.64-77.31)$ \\
\hline \multicolumn{5}{|l|}{ Location of hospitalisation } \\
\hline Public hospital & $31(20.5 \%)$ & $23(19.0 \%)$ & \multirow[t]{2}{*}{$0.755^{*}$} & \\
\hline Private hospitals & $120(79.5 \%)$ & $98(81.0 \%)$ & & \\
\hline \multicolumn{5}{|c|}{ Are you worried about contracting COVID-19 } \\
\hline Minimally worried & $55(36.4 \%)$ & $29(24.0 \%)$ & \multicolumn{2}{|c|}{ Reference group } \\
\hline Average level of worry & $40(26.5 \%)$ & $46(38.0 \%)$ & 0.129 & $1.74(0.85-3.59)$ \\
\hline Very much & $56(37.1 \%)$ & $46(38.0 \%)$ & 0.257 & $1.47(0.76-2.9)$ \\
\hline \multicolumn{5}{|c|}{ Which do you fear the most currently? } \\
\hline COVID-19 & $42(27.8 \%)$ & $24(19.8 \%)$ & \multirow[t]{3}{*}{$0.280^{* *}$} & \\
\hline Cancer & $86(57.0 \%)$ & $82(67.8 \%)$ & & \\
\hline Both equally & $18(11.9 \%)$ & $13(10.7 \%)$ & & \\
\hline None & $5(3.3 \%)$ & $2(1.7 \%)$ & & \\
\hline \multicolumn{5}{|c|}{$\begin{array}{l}\text { Can chemotherapy lower your immunity and increase the } \\
\text { chance of health-related risks due to COVID-19? }\end{array}$} \\
\hline Yes & $111(73.5 \%)$ & 95 (78.5\%) & \multirow[t]{2}{*}{0.527} & \multirow[t]{2}{*}{$0.798(0.40-1.61)$} \\
\hline No & $38(25.2 \%)$ & $22(18.2 \%)$ & & \\
\hline Don't know & $2(1.3 \%)$ & $4(3.3 \%)$ & & \\
\hline
\end{tabular}

All variables listed above were included in the multivariate analysis.

$p$-value $<0.05$ is considered to be significant

$n$, frequency; \%, percentage

* Univariate analysis

** Chi-squared test 
Table 7. Perspective about cancer and COVID-19.

\begin{tabular}{|l|c|}
\hline & $n$ (\%) \\
\hline Are you worried about contracting COVID-19 & $84(30.9 \%)$ \\
\hline Minimally worried & $86(31.6 \%)$ \\
\hline Average level of worry & $102(37.5 \%)$ \\
\hline Very much & \\
\hline $\begin{array}{l}\text { Can chemotherapy lower your immunity and increase the chance of health-related } \\
\text { risks due to COVID-19? }\end{array}$ & $206(75.7 \%)$ \\
\hline Yes & $60(22.1 \%)$ \\
\hline No & $6(2.2 \%)$ \\
\hline Don't know & \\
\hline Which do you fear the most currently? & $66(24.3 \%)$ \\
\hline COVID-19 & $168(61.8 \%)$ \\
\hline Cancer & $31(11.4 \%)$ \\
\hline Both & $7(2.6 \%)$ \\
\hline None & \\
\hline What preventive measures are you taking for COVID 19 at home? & $36(13.2 \%)$ \\
\hline Facemask and social distancing only & $65(23.9 \%)$ \\
\hline Self-quarantine only & $76(28 \%)$ \\
\hline Both & $95(34.9 \%)$ \\
\hline None of the above/other measures & \\
\hline
\end{tabular}

$n$, frequency; \%, percentage

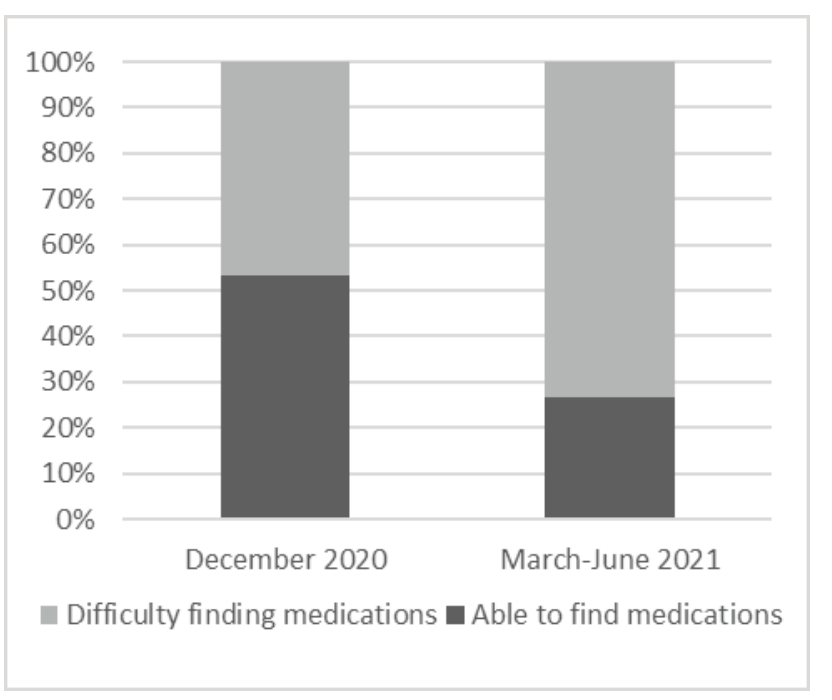

Figure 2. Ability to find other non-chemotherapy medications in December 2020 compared to March-June $2021(p=0.015)$. 
A study was also done on the perspective of cancer patients on 302 participants from India by Ghosh et al [20]. The level of worry regarding contracting COVID-19 was very much in $19 \%$ of participants compared to $37.5 \%$ in this study, moderate in $45 \%$ compared to $31.6 \%$ in this study and minimal in 39\% compared to $30.9 \%$ in this study. Another similar question was if patients feared cancer more that COVID-19 or vice versa, $72 \%$ feared cancer more than COVID-19 compared to 61.8\% in this study and 26\% feared COVID-19 more than cancer compared to $24.3 \%$ in this study. Finally, a third similar question was if patients knew that chemotherapy could cause more health-related outcomes due to COVID-19 where $52 \%$ answered it could, compared to $75.7 \%$ in this study. So, comparing these two populations, we can say that participants in this study reported better knowledge about the immunosuppressive potential of chemotherapy and worse prognosis of COVID-19 infection with $p<0.001$ on chi-squared test. This could be related to good pre-chemotherapy counselling, better recall of information, or simply due to new research published since conducting this study, which clinicians may have used in counselling, also these relatively new findings being available to be accessed by patients on their own.

Some limitations to this study would include, the tool used to assess knowledge level of cancer patients was adapted and validated specifically for this study instead of using an already used and validated scale. Second, we were not able to perform Confirmatory Factor Analysis (CFA) which confirms whether the extracted factor structure truly and adequately describes the data using different model fit indices. Performing CFA would need a second sample which we were not able to provide due to limitations in time, resources as well as limitations induced by the pandemic. Third, due to the barriers imposed by the pandemic, the sample was not designed to statistically represent the population of all cancer patients in Lebanon and make rigid extrapolations, but to give sufficient insight, for the first time, on the challenges, knowledge towards COVID-19 and perspective of this population during the COVID-19 pandemic and concomitant Lebanese financial crisis. Fourth, due to the Hawthorne effect, patients might have given some answers they might perceive as acceptable since they were interviewed in the hospital. Fifth, this study was made in four specific medical centres, excluding other larger chemotherapy units which might have led to selection bias.

\section{Conclusions}

This study shows that cancer patients in Lebanon are facing many challenges that complicate different aspects of health. The majority of these challenges are found in increased proportions in public compared to private hospitals. Also, some challenges are increasing over the timeline of this study, suggesting that Lebanon is in need of rapid interventions in order to help people in their most vulnerable. Finally, the perspective and challenges of cancer patients must be taken into consideration in order to deliver better care during these unprecedented times.

\section{Acknowledgments}

First and foremost, the authors would like to thank all patients who during these challenging times are still fighting all circumstances and consented to participate in this study.

This article is part of a Medical Doctor thesis at the Lebanese University Faculty of Medical Sciences and has been approved by the Thesis Committee as well as the Dean, with reference number 28/2021 for the approval letter.

Finally, the authors would like to thank Dr Christina Khater who contributed by interviewing patients she is caring for at Saint Charles Hospital.

\section{Conflicts of interest}

The authors declare that they have no conflicts of interest. 


\section{Funding}

This research work is not funded by any organisation.

\section{Authors' contributions}

$\mathrm{RN}$, JK and BFM developed the project idea. RN, JK, PS and BFM developed the questionnaire. RN, JK and AK worked on data collection. $\mathrm{RN}, \mathrm{JK}, \mathrm{HS}$ and PS analyzed the data. RN drafted the paper. All authors critically reviewed the manuscript for important intellectual content and agreed on the final version.

\section{References}

1. Liang W, Guan W, and Chen R, et al (2020) Cancer patients in SARS-CoV-2 infection: a nationwide analysis in China Lancet Oncol 21(3) 335-337 https://doi.org/10.1016/S1470-2045(20)30096-6 PMID: 32066541 PMCID: 7159000

2. Garassino MC, Whisenant JG, and Huang LC, et al (2020) COVID-19 in patients with thoracic malignancies (TERAVOLT): first results of an international, registry-based, cohort study Lancet Oncol 21(7) 914-922 https://doi.org/10.1016/S1470-2045(20)30314-4 PMID: 32539942 PMCID: $\underline{7292610}$

3. Al-Quteimat O and Amer A (2020) The impact of the COVID-19 pandemic on cancer patients Am J Clin Oncol 43(6) 452-455 https:// doi.org/10.1097/COC.0000000000000712 PMID: 32304435 PMCID: 7188063

4. Addeo A and Friedlaender A (2020) Cancer and COVID-19: unmasking their ties Cancer Treat Rev 88 102041 https://doi.org/10.1016/j. ctrv.2020.102041 PMID: 32516704 PMCID: 7831797

5. Fillmore NR, La J, and Szalat RE, et al (2020) Prevalence and outcome of COVID-19 infection in cancer patients: a national veterans affairs study JNCl: J Natl Cancer Inst 113(6) 691-698 https://doi.org/10.1093/jnci/djaa159 PMID: 33031532 PMCID: 7665587

6. Lee LYW, Cazier JB, and Starkey T, et al (2020) COVID-19 prevalence and mortality in patients with cancer and the effect of primary tumour subtype and patient demographics: a prospective cohort study Lancet Oncol 21(10) 1309-1316 https://doi.org/10.1016/ S1470-2045(20)30442-3 PMID: 32853557 PMCID: 7444972

7. Yang F, Shi S, and Zhu J, et al (2020) Clinical characteristics and outcomes of cancer patients with COVID-19 J Med Virol 92(10) 20672073 https://doi.org/10.1002/jmv.25972 PMID: 32369209

8. Torre L, Siegel R, and Ward E, et al (2015) Global cancer incidence and mortality rates and trends - an update Cancer Epidemiol Biomarkers Prev 25(1) 16-27 https://doi.org/10.1158/1055-9965.EPI-15-0578 PMID: 26667886

9. Kutikov A, Weinberg D, and Edelman M, et al (2020) A war on two fronts: cancer care in the time of COVID-19 Ann Intern Med 172(11) 756-758 https://doi.org/10.7326/M20-1133 PMID: 32219410 PMCID: 7133056

10. Surveillance in Lebanon (2020) [Internet] [https://www.moph.gov.lb/en/Pages/2/194/surveillance-data\#/en/Pages/2/24870/novelcoronavirus-2019-] Date accessed: 31/12/20

11. World Bank (2021) [Internet] [https://www.worldbank.org/en/country/lebanon/publication/lebanon-economic-monitor-spring2021-lebanon-sinking-to-the-top-3] Date accessed: 29/8/21

12. Das M (2021) Lebanon faces critical shortage of drugs Lancet Oncol 22(8) 1063 https://doi.org/10.1016/S1470-2045(21)00396-X PMID: 34246331 
13. Sturgis $P$, Roberts $C$, and Smith $\mathrm{P}$ (2014) Middle alternatives revisited: how the neither/nor response acts as a way of saying 'I don't know'? Sociol Methods Res 43(1) 15-38 https://doi.org/10.1177/0049124112452527

14. Fornell $C$ and Larcker DF (1981) Evaluating structural equation models with unobservable variables and measurement error J Mark Res 18(1) 39-50 https://doi.org/10.1177/002224378101800104

15. Carmines E and Zeller R (1979) Reliability and Validity Assessment (SAGE Publications)

16. El Saghir NS, Khalil MK, and Eid T, et al (2007) Trends in epidemiology and management of breast cancer in developing Arab countries: a literature and registry analysis Int J Surg 5(4) 225-233 https://doi.org/10.1016/j.ijsu.2006.06.015 PMID: 17660128

17. Lebanon | UNESCO UIS (2021) [Internet] [http://uis.unesco.org/en/country/lb] Date accessed: 16/9/21

18. Mitra M and Basu M (2020) A study on challenges to health care delivery faced by cancer patients in India during the COVID-19 pandemic J Prim Care Community Health 11215013272094270 https://doi.org/10.1177/2150132720942705

19. Li H, Bailey A, and Huynh D, et al (2020) YouTube as a source of information on COVID-19: a pandemic of misinformation? BMJ Glob Health 5(5) e002604 https://doi.org/10.1136/bmjgh-2020-002604 PMID: 32409327 PMCID: 7228483

20. Ghosh J, Ganguly S, and Mondal D, et al (2020) Perspective of oncology patients during COVID-19 pandemic: a prospective observational study from India JCO Glob Oncol 6 844-851 https://doi.org/10.1200/GO.20.00172 PMID: 32552110 PMCID: 7328097 


\section{Supplementary material}

Initially, 15 statements were selected after reviewing the Centers for Disease Control and Prevention and the World Health Organization's websites. A pilot study was then conducted on 30 patients from a single centre at Dar El Amal University Hospital in Baalbek, Lebanon. Reliability statistics were then conducted on the responses of these 30 participants, which yielded a Cronbach's Alpha value of 0.683 (See Supplementary Table 1). As a Cronbach's Alpha value of 0.7 and higher can be considered as reliable, statements numbered 4, 6, 7, 13 and 15 from Supplementary Table 1 were removed in order to increase Cronbach's Alpha to 0.707 which is acceptable (See Supplementary Table 2).

Our study was conducted with the scale shown in Supplementary Table 2 including ten items in total.

Two items ( 2 and 10) were removed later on in the study as they were shown not to be accurate. Item number 2 was removed as runny nose can be a major symptom of COVID-19, and Item number 10 was removed as COVID-19 can present with hair loss due to stress like any other infection.

Supplementary Table 1. Reliability statistics of the 15 initial items of our pilot study.

\begin{tabular}{|l|l|}
\hline Reliability statistics \\
\hline Cronbach's Alpha & N of items \\
\hline 0.683 & 15 \\
\hline
\end{tabular}

\begin{tabular}{|c|c|c|c|c|}
\hline \multicolumn{5}{|l|}{ Item-total statistics } \\
\hline & $\begin{array}{l}\text { Scale mean if item } \\
\text { deleted }\end{array}$ & $\begin{array}{c}\text { Scale variance if item } \\
\text { deleted }\end{array}$ & $\begin{array}{l}\text { Corrected item-total } \\
\text { correlation }\end{array}$ & $\begin{array}{l}\text { Cronbach's alpha if } \\
\text { item deleted }\end{array}$ \\
\hline $\begin{array}{l}\text { 1- Infected children showing no symptoms can } \\
\text { spread the virus to others (Agree) }\end{array}$ & 29.78 & 20.499 & 0.334 & 0.664 \\
\hline $\begin{array}{l}\text { 2- Runny nose is considered a major symptom of } \\
\text { COVID-19 (Disagree) }\end{array}$ & 28.63 & 19.597 & 0.343 & 0.661 \\
\hline $\begin{array}{l}\text { 3- COVID-19 is always accompanied by a loss of } \\
\text { taste and smell, in } 100 \% \text { of people who contract } \\
\text { the virus (Disagree) }\end{array}$ & 29.22 & 19.273 & 0.291 & 0.671 \\
\hline $\begin{array}{l}\text { 4- Diffuse body and throat pain is considered as } \\
\text { symptoms of COVID-19 (Agree) }\end{array}$ & 29.88 & 22.629 & 0.024 & 0.700 \\
\hline 5- COVID-19 can spread through cough (Agree) & 29.97 & 20.676 & 0.434 & 0.658 \\
\hline $\begin{array}{l}\text { 6- COVID-19 spreads in cold weather and does } \\
\text { not spread in warm and humid weather. (Disagree) }\end{array}$ & 28.41 & 21.733 & 0.119 & 0.687 \\
\hline $\begin{array}{l}\text { 7- Influenza vaccine protects from contracting } \\
\text { COVID-19 (Disagree) }\end{array}$ & 28.41 & 22.055 & 0.132 & 0.683 \\
\hline $\begin{array}{l}\text { 8- COVID-19 can spread through food through } \\
\text { the digestive system (Disagree) }\end{array}$ & 29.00 & 18.903 & 0.362 & 0.658 \\
\hline $\begin{array}{l}\text { 9- Hot beverages protect from contracting } \\
\text { COVID-19 (Disagree) }\end{array}$ & 28.94 & 18.641 & 0.512 & 0.636 \\
\hline $\begin{array}{l}\text { 10- Hair loss is considered a symptom of } \\
\text { COVID-19 (Disagree) }\end{array}$ & 28.81 & 19.770 & 0.364 & 0.658 \\
\hline $\begin{array}{l}\text { 11- Eating garlic protects from contracting } \\
\text { COVID-19 (Disagree) }\end{array}$ & 28.69 & 20.673 & 0.324 & 0.665 \\
\hline
\end{tabular}




\begin{tabular}{|l|c|c|c|}
\hline $\begin{array}{l}\text { 12- COVID-19 can spread through the water of } \\
\text { swimming pools (Disagree) }\end{array}$ & 28.91 & 19.830 & 0.349 \\
\hline $\begin{array}{l}\text { 13- COVID-19 can spread through mosquito } \\
\text { stings (Disagree) }\end{array}$ & 28.53 & 21.289 & 0.660 \\
\hline $\begin{array}{l}\text { 14- Wearing a face shield without a mask protects } \\
\text { from contracting COVID-19 (Disagree) }\end{array}$ & 28.63 & 19.016 & 0.241 \\
\hline $\begin{array}{l}15-\text { You should not wear a face mask while } \\
\text { exercising at the gym (Agree) }\end{array}$ & 29.53 & 20.902 & 0.427 \\
\hline
\end{tabular}

Agree/Disagree in the parentheses denotes the intended correct answer

Supplementary Table 2. Reliability statistics after deleting items 4, 6, 7, 13 and 15.

\begin{tabular}{|l|l|}
\hline Reliability statistics & N of items \\
\hline Cronbach's Alpha & 10 \\
\hline 0.707 & \\
\hline
\end{tabular}

\begin{tabular}{|c|c|c|c|c|}
\hline \multicolumn{5}{|l|}{ Item-total statistics } \\
\hline & $\begin{array}{l}\text { Scale mean if item } \\
\text { deleted }\end{array}$ & $\begin{array}{c}\text { Scale variance if item } \\
\text { deleted }\end{array}$ & $\begin{array}{l}\text { Corrected item-total } \\
\text { correlation }\end{array}$ & $\begin{array}{l}\text { Cronbach's alpha if } \\
\text { item deleted }\end{array}$ \\
\hline $\begin{array}{l}\text { 1- Infected children showing no symptoms can } \\
\text { spread the virus to others (Agree) }\end{array}$ & 19.06 & 15.415 & 0.273 & 0.699 \\
\hline $\begin{array}{l}\text { 2- Runny nose is considered a major symptom of } \\
\text { COVID-19 (Disagree) }\end{array}$ & 17.91 & 13.894 & 0.415 & 0.676 \\
\hline $\begin{array}{l}\text { 3- COVID-19 is always accompanied by a loss of } \\
\text { taste and smell, in } 100 \% \text { of people who contract } \\
\text { the virus (Disagree) }\end{array}$ & 18.50 & 13.613 & 0.347 & 0.692 \\
\hline 5- COVID-19 can spread through cough (Agree) & 19.25 & 15.613 & 0.349 & 0.692 \\
\hline $\begin{array}{l}\text { 8- COVID-19 can spread through food through } \\
\text { the digestive system (Disagree) }\end{array}$ & 18.28 & 13.499 & 0.394 & 0.681 \\
\hline $\begin{array}{l}\text { 9- Hot beverages protect from contracting } \\
\text { COVID-19 (Disagree) }\end{array}$ & 18.22 & 13.660 & 0.485 & 0.664 \\
\hline $\begin{array}{l}\text { 10- Hair loss is considered a symptom of } \\
\text { COVID-19 (Disagree) }\end{array}$ & 18.09 & 14.217 & 0.412 & 0.677 \\
\hline $\begin{array}{l}\text { 11- Eating garlic protects from contracting } \\
\text { COVID-19 (Disagree) }\end{array}$ & 17.97 & 15.451 & 0.286 & 0.697 \\
\hline $\begin{array}{l}\text { 12- COVID-19 can spread through the water of } \\
\text { swimming pools (Disagree) }\end{array}$ & 18.19 & 14.738 & 0.311 & 0.694 \\
\hline $\begin{array}{l}\text { 14- Wearing a face shield without a mask protects } \\
\text { from contracting COVID-19 (Disagree) }\end{array}$ & 17.91 & 13.830 & 0.427 & 0.674 \\
\hline
\end{tabular}

Agree/Disagree in the parentheses denotes the intended correct answer. 